\title{
Strain relaxation and self-organization phenomena in heteroepitaxial systems
}

Shiryaev, Sergey Y; Hansen, J. Lundsgaard; Larsen, A. Nylandsted; Jensen, Flemming; Petersen, Jon Wulff

Published in:

Physical Review B

Link to article, DOI:

10.1103/PhysRevB.52.15881

Publication date:

1995

Document Version

Publisher's PDF, also known as Version of record

Link back to DTU Orbit

Citation (APA):

Shiryaev, S. Y., Hansen, J. L., Larsen, A. N., Jensen, F., \& Petersen, J. W. (1995). Strain relaxation and selforganization phenomena in heteroepitaxial systems. Physical Review B, 52(22), 15881-15888.

https://doi.org/10.1103/PhysRevB.52.15881

\section{General rights}

Copyright and moral rights for the publications made accessible in the public portal are retained by the authors and/or other copyright owners and it is a condition of accessing publications that users recognise and abide by the legal requirements associated with these rights.

- Users may download and print one copy of any publication from the public portal for the purpose of private study or research.

- You may not further distribute the material or use it for any profit-making activity or commercial gain

- You may freely distribute the URL identifying the publication in the public portal

If you believe that this document breaches copyright please contact us providing details, and we will remove access to the work immediately and investigate your claim 


\title{
Strain relaxation and self-organization phenomena in heteroepitaxial systems
}

\author{
S. Yu. Shiryaev, J. Lundsgaard Hansen, and A. Nylandsted Larsen \\ Institute of Physics and Astronomy, Aarhus University, DK-8000 Aarhus C, Denmark \\ F. Jensen and J. Wulff Petersen \\ Mikroelektronik Centre, Building 345 East, The Technical University of Denmark, DK-2800 Lyngby, Denmark
}

(Received 2 May 1995)

\begin{abstract}
The plastic behavior of strained, compositionally graded $\mathrm{Si}_{1-x} \mathrm{Ge}_{x}$ alloy layers grown on $\mathrm{Si}$ substrates has been studied by a combination of optical, atomic force, and transmission electron microscopy. Formation of ordered patterns of misfit dislocations has been found in films grown at low $\left(\sim 500^{\circ} \mathrm{C}\right)$ temperatures, and examined at different length scales. We demonstrate that the strain relaxation in the thick metastable layers is an evolutionary propagative process, which is heterogenous from the very beginning and localized in narrow shear bands. It is shown that the relaxation process is characterized by dissipation of large amounts of the elastic internal energy accumulated during film growth and takes place far away from thermodynamic equilibrium. These results strongly suggest that the dislocation patterning in graded layers involves selforganization of dislocation populations. Striking analogies between the Seeger-Frank treatment of dislocation ordering in solids and the model of self-adjustment of misfit dislocations are elaborated. The graded $\mathrm{Si}_{1-x} \mathrm{Ge}_{x} / \mathrm{Si}$ system will be shown to constitute a convenient model case for studying self-organization in crystalline material.
\end{abstract}

\section{INTRODUCTION}

The remarkable developments made in the field of crystal plasticity during the last decade are based on the recognition that the ordered dislocation patterns and shear bands found in solids after heavy deformation belong to the category of synergetic steady-state structures. ${ }^{1-3}$ In general, the synergetic approach regards a crystal undergoing plastic deformation as a nonlinear, dynamical, highly dissipative system in which, under certain conditions, the dislocation populations are prone to organize themselves into spatial or spatiotemporal macroscopic structures. Such an approach is consistent with the inherent irreversibility of deformation processes and is valid for a broad range of plasticity phenomena. ${ }^{1-3}$ One exception was believed to be the relaxation of the lattice mismatch strain in heteroepitaxial film systems. The central point of the theory of the mismatch epitaxy is a relaxation of an epilayer/substrate system to an equilibrium state by the introduction of misfit dislocations at the epilayer/substrate interface. ${ }^{4,5}$ The regular dislocation arrays observed in a large number of heteroepitaxial systems ${ }^{6-8}$ are well understood in the scope of this thermodynamic context; i.e., their regularity is directly related to the requirement of minimum total energy. In this sense, such dislocation configurations may be considered as an example of a situation where equilibrium is the source of order.

The purpose of this work is manyfold: We represent new data on the development of the dislocation structure in compositionally graded $\mathrm{Si}_{1-x} \mathrm{Ge}_{x} / \mathrm{Si}$ systems and show that the relaxation in thick, metastable films is provided by the formation of dislocation patterns different from those expected from thermodynamic considerations. We anchor the observed dislocation patterns within the framework of a synergetic approach by recognizing thick strained epilayers as open, dissipative systems in which the patterning is a result of cooperative behavior of dislocation populations. Remarkable analogies between the Seeger-Frank treatment of synergetic ordering in solids ${ }^{3}$ and the model of self-adjustment of misfit dislocations ${ }^{9}$ are elaborated.

\section{EXPERIMENTAL PROCEDURE}

The studies were performed on graded $\mathrm{Si}_{1-x} \mathrm{Ge}_{x}$ films grown on (001) $\mathrm{Si}$ in a VG Semicon V80 molecular beam epitaxy (MBE) system equipped with two electron guns for evaporation of $\mathrm{Si}$ and $\mathrm{Ge}$. The growth temperature of $530{ }^{\circ} \mathrm{C}$ and the total growth rate ( $\mathrm{Si}$ plus $\mathrm{Ge}$ ) of $0.5 \mathrm{~nm} / \mathrm{s}$ were kept constant during the growth procedure. On all samples a $1-\mu \mathrm{m} \mathrm{Si}$ buffer layer was grown first, followed by the deposition of the graded layer where the Ge content was linearly increased with a Ge concentration gradient of $15 \%$ Ge per micrometer. The growth was terminated at different thickness (between 0.5 and $2 \mu \mathrm{m}$ ) in order to study samples of different degrees of relaxation. Unrelaxed samples were further annealed at elevated temperatures (between 600 and $700{ }^{\circ} \mathrm{C}$ ) in a conventional furnace, and some samples were annealed in a rapid thermal annealing (RTA) system at 700, 800 , and $900^{\circ} \mathrm{C}$. For comparison, several samples were grown at high $\left(850{ }^{\circ} \mathrm{C}\right)$ temperature with the same $\mathrm{Ge}$ concentration gradient as for the low growth temperature. Optical, transmission electron, and atomic force microscopy (AFM) were employed for the structural characterization of the graded layers at different length scales. The AFM studies were performed in air with a fully automated commercial instrument as described elsewhere. ${ }^{10}$ Transmission electron microscopy (TEM) analysis was performed in a Philips CM20 microscope operating at $200 \mathrm{keV}$.

\section{RESULTS}

In the first part of our experiments, the AFM investigations were performed on unrelaxed, metastable samples 

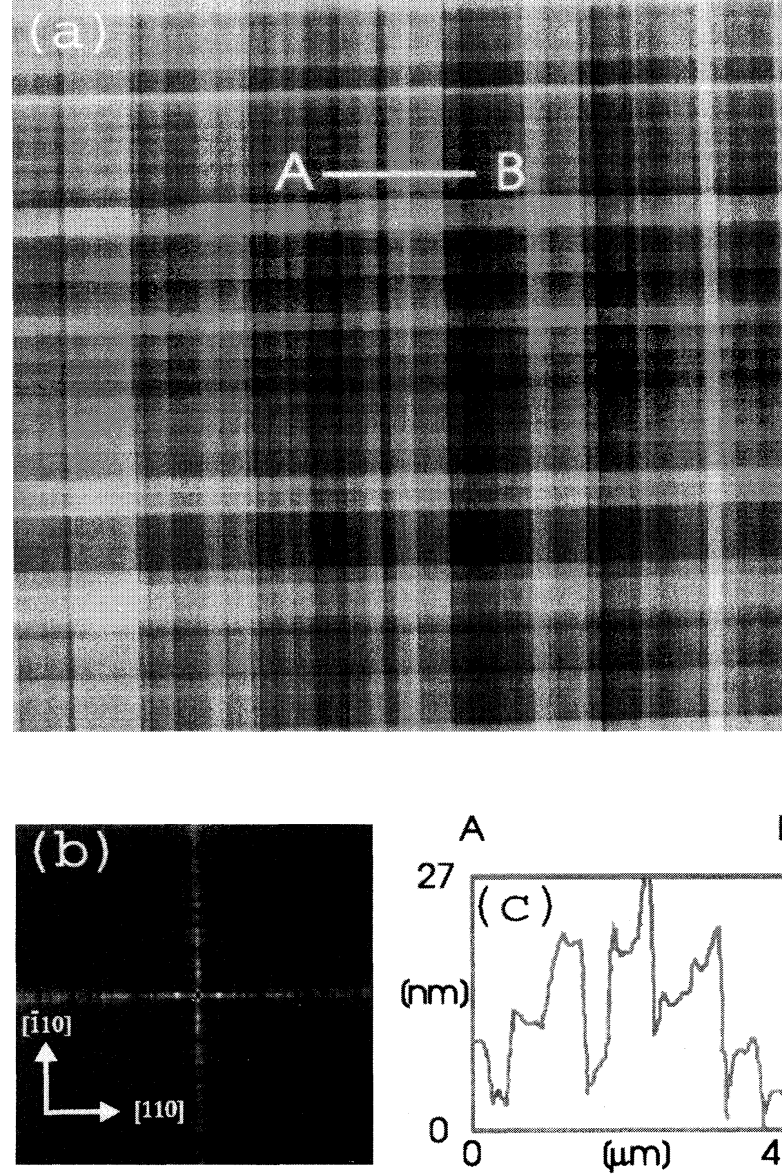

A

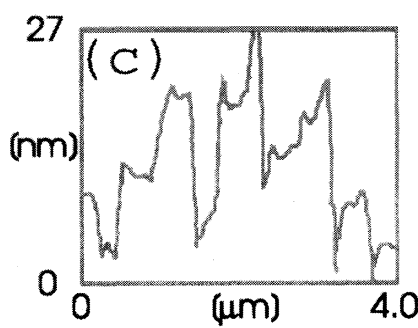

FIG. 1. AFM $\left(21 \times 21 \mu^{2}\right)$ image (a) of the slip-band pattern on the surface of a graded layer with a thickness of $1.5 \mu \mathrm{m}$ and a Ge gradient of $15 \%$ Ge per $1 \mu \mathrm{m}$, grown at $530^{\circ} \mathrm{C}$, after annealing at $620^{\circ} \mathrm{C}$ for $1 \mathrm{~h}$. The height scale (black to white) is $47 \mathrm{~nm}$. (b) and (c). Two-dimensional Fourier transform and a height profile (along the displayed line $A B$ ) obtained from (a).

grown at low temperature, in which strain relief was achieved mainly during postgrowth heat treatment at elevated temperatures. It was shown in our previous paper ${ }^{10}$ that such a procedure allows the detection of the mechanical shears caused by the dislocation glide process and thus to map the lateral distributions of the dislocations at mesoscopic length scale. Figure 1(a) is a typical AFM map of the surface shears observed in a $\mathrm{Si}_{1-x} \mathrm{Ge}_{x}$ film graded to a final Ge content of $\sim 22 \%$ and annealed at $620^{\circ} \mathrm{C}$ for $1 \mathrm{~h}$. The surface morphology is represented by a pronounced shearband pattern composed of a variety of $\langle 110\rangle$-rectangular blocks displaced relative to each other in a direction parallel to the surface normal. Such a surface morphology corresponds well to the TEM images of the bands of the $60^{\circ}$ dislocations shown in the plan-view micrograph in Fig. 2. A comparison of the micrographs obtained at different diffraction conditions shows that the dominant part of the dislocations in each band have the same Burgers vectors. It was also found that the TEM images of some dislocations with the same Burgers vector in the shear bands intersect each other in the projection on the film plane. Since such intersections

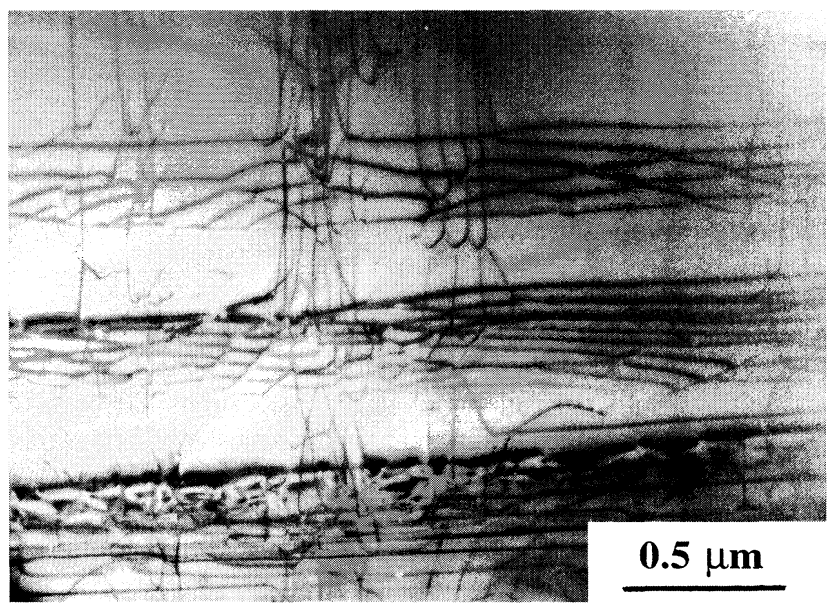

FIG. 2. Typical plan-view TEM image ( $\mathbf{g}=220$, bright field) of the slip bands observed in the sample shown in Fig. 1.

would be impossible if these dislocations lie on the same glide plane, we conclude that at least a part of the dislocations in the shear bands is distributed in parallel slip planes. A cross-sectional TEM micrograph of the sample shown in Fig. 2 is represented in Fig. 3. Well-defined accumulations of misfit dislocations gliding in the same or closely separated slip planes are seen in both the graded layer and beneath the interface plane. This result is consistent with earlier findings ${ }^{11}$ of dislocation pileups penetrating deep into the substrate in graded $\mathrm{Si}_{1-x} \mathrm{Ge}_{x} / \mathrm{Si}$ systems with much higher grading gradients, fabricated by epitaxial growth at low $\left(\sim 500{ }^{\circ} \mathrm{C}\right)$ temperatures.

From the relation between the mismatch strain and the

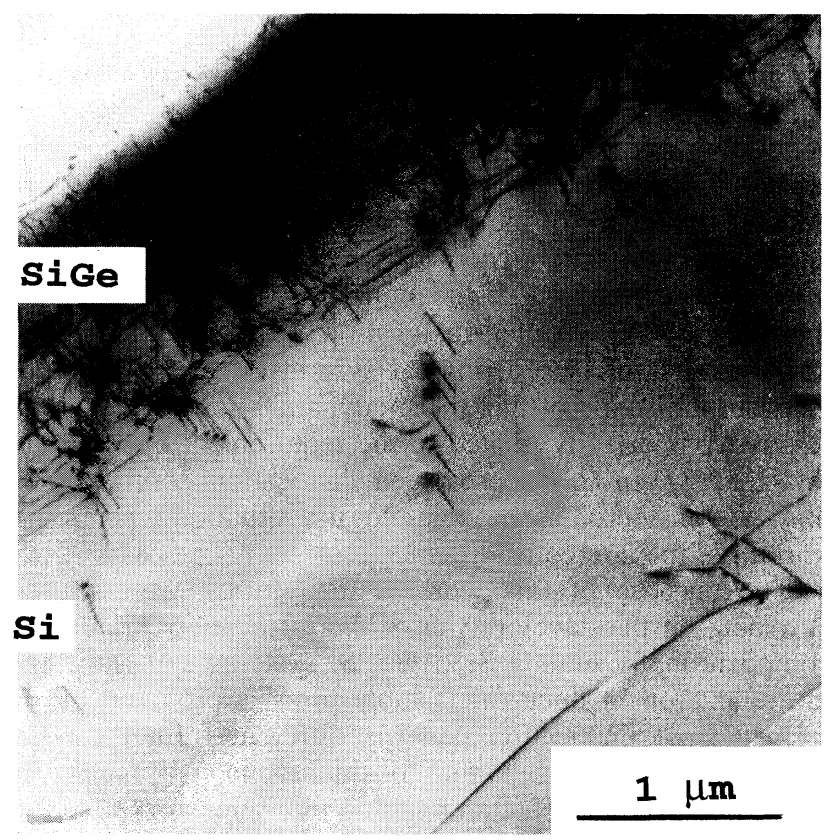

FIG. 3. Cross-sectional bright-field TEM micrograph of the sample shown in Fig. 2. The electron beam direction is about $30^{\circ}$ away from the [110] normal to the specimen plane. 
density of misfit dislocations, ${ }^{6}$ the average dislocation spacing in the fully relaxed film in the sample shown in Fig. 1 should be $20.3 \mathrm{~nm}$. Compared to the measured minimum average dislocation spacing $(40 \mathrm{~nm})$, this value shows that the dislocation distribution in each individual slip band accommodates only a part of the mismatch strain in the film volume covered by this band. Note that the dislocation spacing would be lower and, thus, the strain accommodation would reach a higher level if the full band (including dislocations located in the substrate) is compressed to the region of the graded film. This does not occur, indicating that the repulsive interactions between dislocations with the same Burgers vectors in the shear bands contribute significantly to the total force balance controlling the equilibrium distribution of the misfit dislocations. This conclusion is important for the discussions below, as it shows that the energy of interaction between misfit dislocations in our samples is dominated by the energy associated with the repulsive interactions.

Further analysis of the AFM images of relaxed samples shows that the shear-band patterns are long-range coherent: i.e., the patterns are dominated by bands which are continuous over areas of at least $30 \times 30 \mu \mathrm{m}^{2}$, corresponding to the maximum scanned area. Optical micrographs revealed that the length of some slip bands reaches a value of up to 0.2 $\mathrm{mm}$.

Another striking feature of the band patterns is that the shear bands are ordered as follows from the Fourier transform [Fig. 1(b)] of the pattern in Fig. 1(a). The intensity distribution in the Fourier transform includes a number of "diffraction" spots along the $\langle 110\rangle$ surface directions. Some particular spots have very big intensities, indicating the existence of typical repetition distances along the $\langle 110\rangle$ directions in the studied area.

Figure 4 illustrates the dependence of the dislocation patterns on annealing time in a $1-\mu \mathrm{m}$-thick film. No indication of slip bands was found in the as-grown samples by the AFM technique. Annealing at $620^{\circ} \mathrm{C}$ results in the appearance of a block-shaped surface morphology in which the average lateral size of the rectangular blocks scales down with annealing time. The relative $z$ displacements of the surface blocks $(0.5-5 \mathrm{~nm})$, however, remain constant during annealing. These results show that the plastic activity in the graded films is confined to the slip bands right from the early stage of the relaxation process and that the relaxation proceeds by increasing the slip-band density.

In order to determine the influence of annealing temperature on dislocation structure in the metastable graded films, we annealed $1.5-\mu \mathrm{m}$-thick samples by RTA at 700,800 , and $900{ }^{\circ} \mathrm{C}$ for $10 \mathrm{~s}$. No effect of the annealing temperature on the general morphology of the dislocation arrangements was found: i.e., in all cases, dislocation patterns were composed of narrow slip bands, similar to those shown in Fig. 1.

The analysis performed above also demonstrates that AFM and TEM are a very useful combination of experimental techniques which compliment each other in the study of dislocation structures in graded layers at microscopic (TEM) and mesoscopic (AFM) length scales. The analysis below will extend the characterization of the dislocation structures to a macroscopic length scale.

To study how the dislocation patterns develop during
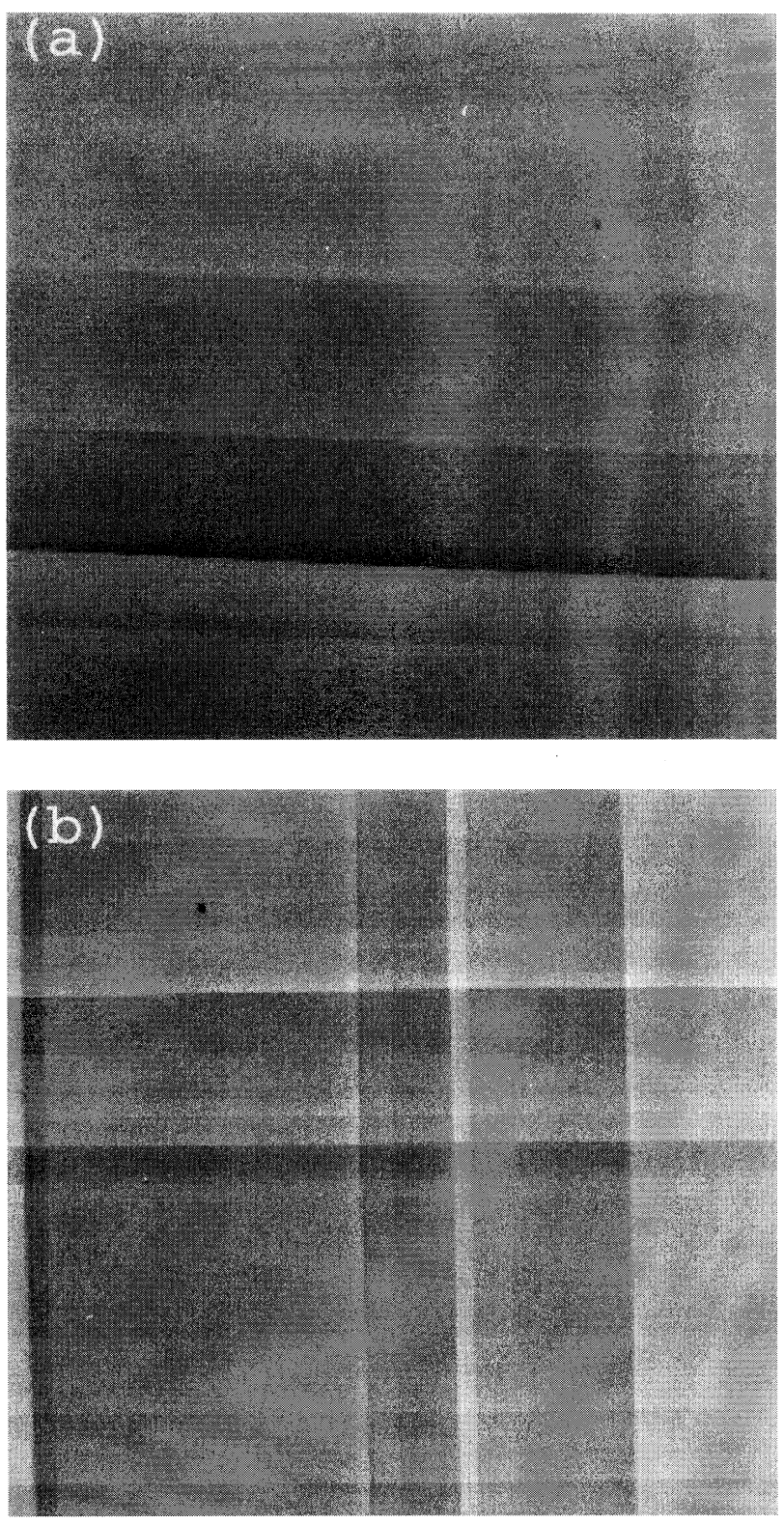

FIG. 4. AFM images characterizing the development of the slipband pattern in a $1-\mu \mathrm{m}$-thick graded layer grown at $530^{\circ} \mathrm{C}$, during the postgrowth heat treatment at $620^{\circ} \mathrm{C}$. The annealing time is 10 min (a) and $40 \mathrm{~min}$ (b), respectively. The scanned area and the height scale are $14 \times 14 \mu \mathrm{m}^{2}$ and $20 \mathrm{~nm}$, respectively, on all images.

growth at low temperature $\left(530^{\circ} \mathrm{C}\right)$, we terminated the growth at different film thicknesses and analyzed the samples by TEM and a combination of preferential chemical etch and optical microscopy. The following three characteristic stages in the development of the dislocation patterns were found.

(1) At the very beginning, the plastic activity is localized to dislocation arrangements seen as cross-shaped structures [Fig. 5(a)]. The density of the cross-shaped defects was found to be about $7 \times 10^{2} \mathrm{~cm}^{-2}$. The corresponding dislocation structures revealed by TEM are shown in Fig. 6: A single band of the $60^{\circ}$ misfit dislocations with the same Burgers vector is seen in Fig. 6(a); a more complicated structure 
(a)

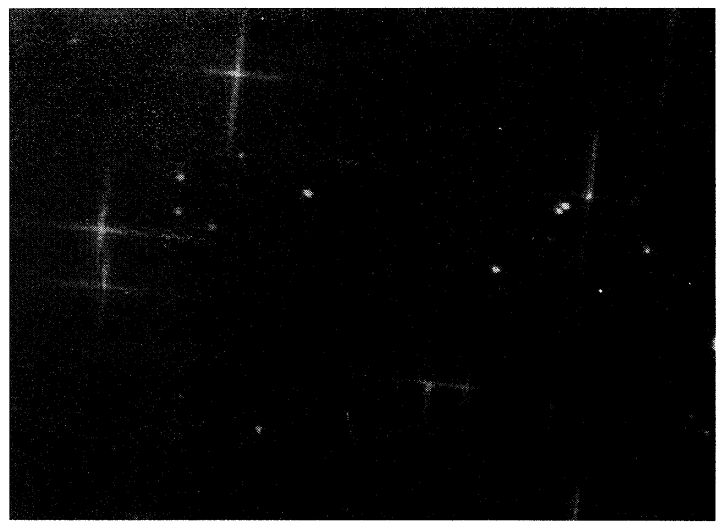

(b)

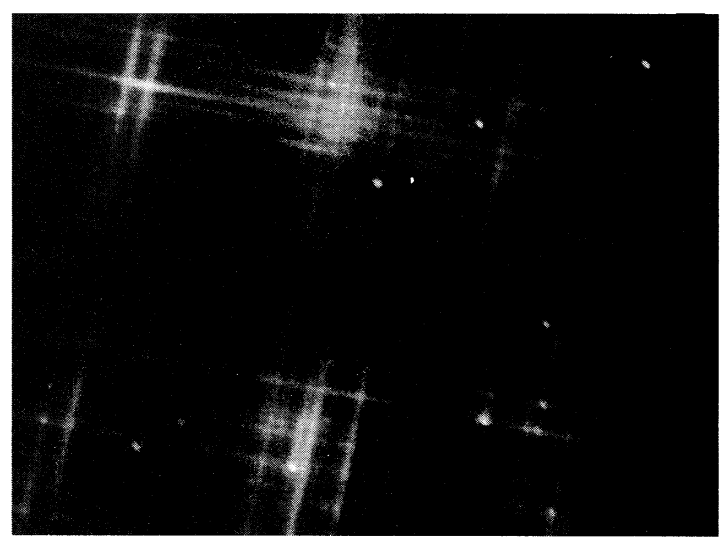

(c)

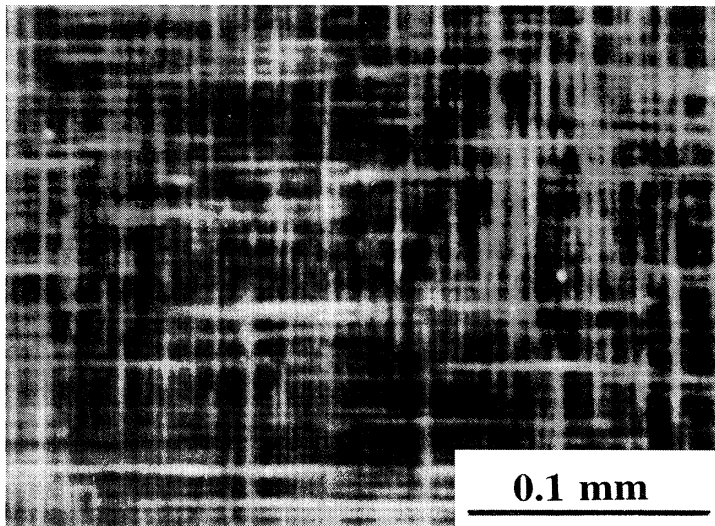

FIG. 5. Development of the slip-band pattern in graded layers during growth at $530^{\circ} \mathrm{C}$, as revealed by the optical microscopy combined with the preferential chemical etch technique. The structures are (a) 1- and (b) 1.5- $\mu \mathrm{m}$-thick graded layers, and (c) $2-\mu \mathrm{m}$ graded layer plus $2-\mu \mathrm{m}$ uniform cap.

composed of a central defect and orthogonal dislocation bands of $60^{\circ}$ dislocations is shown in Fig. 6(b). No indication of single, isolated dislocations was found. Detailed TEM analysis indicates that the majority of individual dislocations in each band in Fig. 6(b) have the same Burgers vectors, but that these vectors are different for the different bands. Because of the lack of observation of any other defects in the specimens, we conclude that the cross-shaped features revealed by optical microscopy are composed of dislocation bands similar to those shown in Fig. 6 . (a)

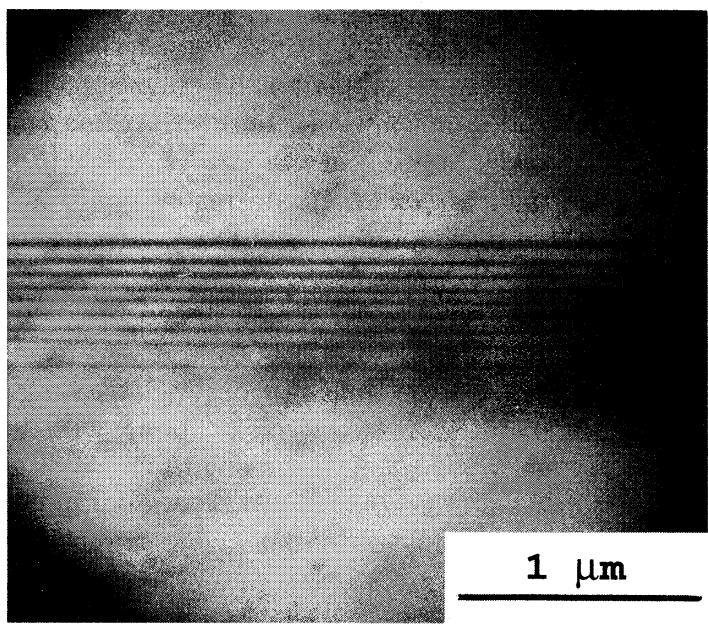

(b)

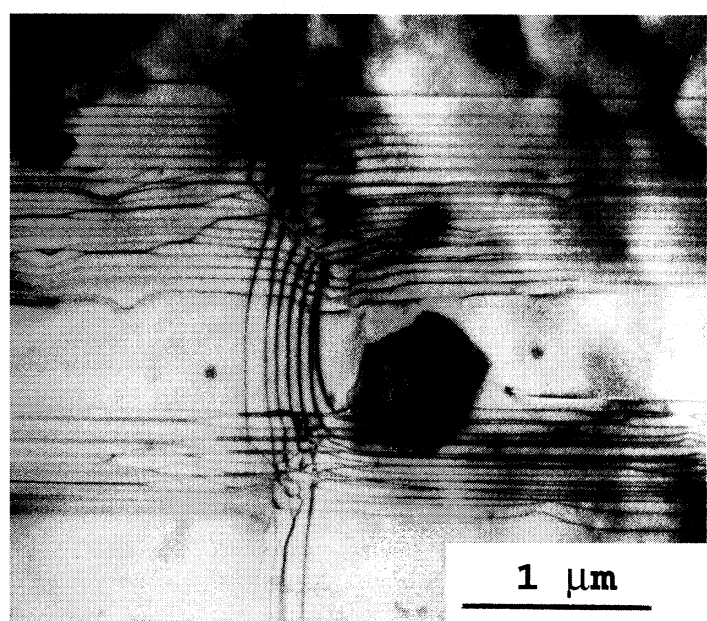

FIG. 6. Plan-view bright-field TEM images of the 1- $\mu$ m-thick graded layer grown at $530{ }^{\circ} \mathrm{C}$ : (a) the separated slip band and (b) the more complicated structure composed of the central defect and the orthogonal intersecting slip bands.

(2) The next relaxation stage is characterized by the formation of the second-generation slip bands surrounding the cross-shaped structures, which results in the appearance of the patch pattern shown in Fig. 5(b). The dominant part of the slip bands composing the patches is the newly generated bands branching from the cross-shaped defects, although the slip bands from some patches penetrate into other patches. TEM studies reveal two new characteristic features in the dislocation structure: (i) Single isolated dislocations are found together with the slip bands [Fig. 7(a)], and (ii) the intersections between the orthogonal dislocations include a number of bowing loops [an example is shown in Fig. 7(b)], which can potentially lead to a multiplication event.

(3) The last relaxation stage involves two major processes: (i) The average size of the unit cell of the slip-band network in each patch further decreases due to the formation of new slip bands, and (ii) the patches expand and a large amount of slip bands from individual patches penetrates into the neighboring patches, producing in this way a continuous slip-band pattern [Fig. 5(c)]. In a number of areas in Fig. 5(c) 
(a)

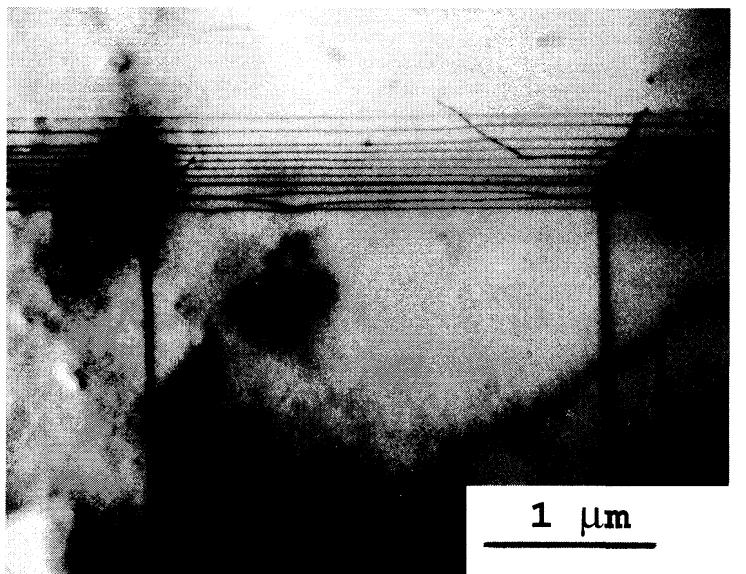

(b)

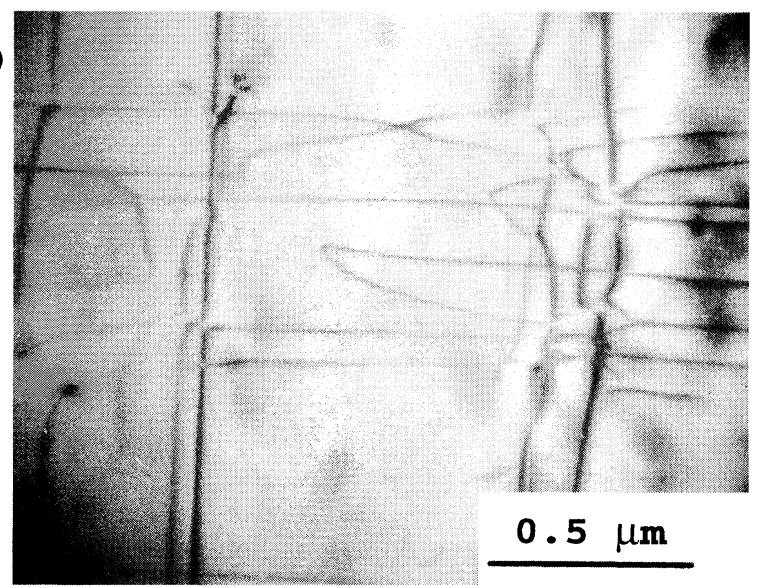

FIG. 7. Plan-view bright-field TEM images of the dislocation structures observed in the $1.5-\mu \mathrm{m}$-thick graded layers grown at $530{ }^{\circ} \mathrm{C}$ : (a) the structure composed of the slip bands and individual dislocations and (b) the intersections of misfit dislocations involving well-defined bowing loops.

one can clearly see the periodicity in the band distribution.

It should be pointed out that cross-shaped defects and patch patterns of misfit dislocations have previously been found in thick, uniform $\mathrm{Si}_{1-x} \mathrm{Ge}_{x}$ films by using the preferential etch ${ }^{12}$ or x-ray topography techniques. ${ }^{13}$ It was shown that the appearance of the cross-shaped structures is a result of the operation of the heterogeneous dislocation generation sources, which can originate from particulate, ${ }^{14}$ diamondlike defects, ${ }^{15}$ and other structural or compositional nonuniformities possible in the MBE-grown material. The authors also suggested several mechanisms of patch-pattern formation, which involve cross slip and multiplication of precursor dislocations composing cross-shaped defects. Although the patch structures and their development in our case are different from those observed in Refs. 12, 13, we conclude that in general the formation of the dislocation patterns in our samples can involve similar mechanisms.

To study the effect of growth temperature on the dislocation patterns in the graded layers, we also looked at samples grown at high $\left(850^{\circ} \mathrm{C}\right)$ temperature. The typical dislocation structure revealed in these samples by TEM is shown in Fig. 8. Compared to the case of the low-temperature growth, the

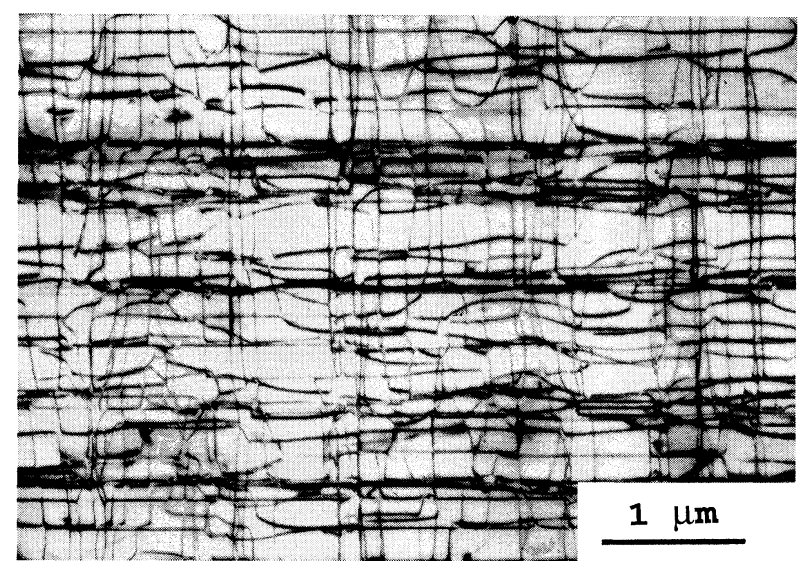

FIG. 8. Typical TEM image of the dislocation pattern found in a $1-\mu \mathrm{m}$-thick graded layer with a Ge gradient of $15 \%$ Ge per $1 \mu \mathrm{m}$, grown at high $\left(850^{\circ} \mathrm{C}\right)$ temperature.

distribution of misfit dislocations in the samples grown at high temperature is much more uniform and is represented by a complicated mixture of dislocation accumulations and randomly distributed dislocations. The first misfit dislocations were found in the films with a thickness of $0.4 \mu \mathrm{m}$.

\section{DISCUSSION}

From the results presented above, it can be concluded that a long-range coherent, ordered slip-band structure is a dominant element of the dislocation arrangements formed in metastable, compositionally graded $\mathrm{Si}_{1-x} \mathrm{Ge}_{x}$ epilayers grown at low temperatures. The occurrence of the slip-band morphology is found to be independent of annealing temperature, which suggests that the formation of the slip bands is related to the metastability of thick $\mathrm{Si}_{1-x} \mathrm{Ge}_{x}$ graded epilayers, rather than to temperature effects. The process of the strain relaxation is found to be propagative - it begins in a small number of well-separated regions and spreads from these regions into the entire film-and evolutionary-it is characterized by several stages with growing complexity in the structural relationships of the dislocation arrangements.

Two kinds of order are found to be characteristic of the observed dislocation patterns: The first kind is represented at a microscopic length scale as the accumulation of misfit dislocations with the same Burgers vector on close-spaced slip planes. This arrangement is certainly a less random structure than a uniform dislocation distribution. The second kind is represented at a mesoscopic length scale by the longrange coherency of the slip-band patterns and by the quasiperiodic character of the band distribution. In the following we will consider basic principles associated with the formation of the observed dislocation patterns.

\section{A. Thermodynamics and heat dissipation in heteroepitaxial systems}

A thermodynamic approach based on minimization of the total energy of the system can not be helpful in the explanation of the slip-band formation: first, because the bands of misfit dislocations with the same Burgers vectors, which penetrate deep into the substrate and accumulate the 
repulsive-interaction energy, are certainly not the lowestenergy dislocation arrangements possible in epitaxial $\mathrm{Si}_{1-x} \mathrm{Ge}_{x} / \mathrm{Si}$ systems (e.g., a random mixture of $60^{\circ}$ dislocations with different Burgers vectors would give a lower total energy due to the existence of attractive interactions between neighboring defects ${ }^{16}$ ); second, because the thermodynamic approach ignores the process by which dislocation structures evolve in the system. This process is irreversible in nature and can involve a variety of dynamic interactions between dislocations, which restricts the application of thermodynamics and is of crucial importance for the understanding of the relaxation behavior even in more simple heteroepitaxial structures. ${ }^{6-8}$

We propose that the dislocation patterns found in the metastable films should be treated as synergetic structures, ${ }^{1-3}$ which, in contrast to equilibrium structures, appear as a result of dynamical interactions between dislocations at farfrom-equilibrium conditions. It was suggested by Seeger and Frank in their general treatment of dislocation ordering in solids ${ }^{3}$ that the distance from equilibrium is a measure of the tendency towards self-organization and that this distance can be estimated as the ratio

$$
K_{d}=W_{s} / W_{\epsilon}
$$

of the energy $W_{s}$ stored in the dislocation structure of the plastically deformed crystals to the mechanical work $W_{\epsilon}$ done during deformation. Actually, the value of $\left(1-K_{d}\right)$ is a relative measure of the external energy dissipated as heat. In plastically deformed metals, $K_{d}$ is typically of the order of $0.1,{ }^{3}$ which implies that about $90 \%$ of the mechanical energy is dissipated. Based on energy calculations, we will now demonstrate that thick, metastable, heteroepitaxial films undergoing strain relaxation also belong to the category of highly dissipative systems, which justifies the consideration of the dislocation patterns in these structures within the concept of self-organization.

Heteroepitaxial films have several unique properties: In contrast to, e.g., plastic deformation of crystals, the work during relaxation is done by internal forces at the cost of internal lattice-mismatch energy accumulated during film growth. One part of this energy is stored in the lattice distortions associated with the misfit dislocations, and the rest is dissipated as heat. Thus the general energy balance equation can be written as

$$
\delta E=E_{d}+Q
$$

where $\delta E$ is the total amount of lattice-mismatch energy transformed in the system during relaxation to a lower strain state, $E_{d}$ is the strain energy stored in dislocation arrangements, and $Q$ is the released heat. Another unique feature of heteroepitaxial films is that the self-stress field of misfit dislocations is coupled with the mismatch stress field in a manner which provides reduction of the applied force during introduction of dislocations in the system. ${ }^{17,18}$

Taking into account these features, we define the dissipation coefficient $\left(K_{d e}\right)$ for heteroepitaxial film systems as the ratio

$$
K_{d e}=Q / \delta E=1-E_{d} / \delta E
$$

For a uniform $\mathrm{Si}_{1-x} \mathrm{Ge}_{x}$ film on a (001) $\mathrm{Si}$ substrate, the value of $K_{d e}$ can be estimated (see the Appendix) by using the expressions for the total and dislocation energy given by Willis et al. ${ }^{17}$ and Gosling et al. ${ }^{18}$ For illustration we have calculated the value $K_{d e}$ for a 200-nm-thick, fully strained, uniform $\mathrm{Si}_{0.9} \mathrm{Ge}_{0.1}$ film which relaxes to the equilibrium state. We found a $K_{d e}$ value around 0.8 , which means that about $80 \%$ of the internal energy is dissipated as heat. For thicker films the value of $K_{d e}$ increases almost as a first power of $h$ because of the density of misfit dislocations and, hence, the dislocation energy $E_{d}$ changes only slightly with $h$, while the value of $\delta E$ increases approximately proportional to $h$.

Similar conclusions are valid for systems containing metastable graded layers. The elastic mismatch energy per unit area in the linearly graded films increases as a third power of $h$, while the areal density of the misfit dislocations required for the strain accommodation, and thus the energy stored in dislocation arrangements in the thick graded films increases approximately linearly with $h .^{19,20}$ Thus an increase of the net internal energy dissipated as heat with the film thickness is even more dramatic than in the case of uniform layers.

The nonequilibrium state of the graded films growing at low temperatures can be seen from different experimental facts, indicating that the relaxation occurs at a large excess of the strain energy: In our films grown at $530^{\circ} \mathrm{C}$, the first misfit dislocations appear at a film thickness of $\sim 1 \mu \mathrm{m}$, while in similar films grown at $850^{\circ} \mathrm{C}$ the dislocations were found at a much lower film thickness of $0.4 \mu \mathrm{m}$. The $\mathrm{x}$-raydiffraction measurements performed by Mooney et al. ${ }^{21}$ for low growth temperatures $\left(500\right.$ or $560{ }^{\circ} \mathrm{C}$ ) show that thick uniform films (thicker than about $1 \mu \mathrm{m}$ ) have to be deposited on the top of graded layers to cause almost full relaxation.

The importance of the distance from equilibrium for the dislocation patterning in graded films can be seen from a comparison of the dislocation morphologies developing in the layers grown at low and high temperatures. In the latter case, the strain relaxation occurs in quasi equilibrium conditions; i.e., the dislocation kinetics allows only for small deviations from equilibrium. ${ }^{19}$ Although dislocation accumulations are also seen in these samples, TEM observations show that the distribution of misfit dislocations is much more uniform than in the films which relax at far-from-equilibrium conditions.

Even though the above analysis allows us to identify the strain relaxation in thick metastable heteroepitaxial films as an irreversible process characterized by dissipation of a large amount of the elastic energy stored during growth, it does not explain the structural mechanisms responsible for the patterning process. The possible mechanisms operating at the microscopic level are discussed in the next section.

\section{B. Patterning mechanisms}

In the heteroepitaxial films systems, the dissipated heat is composed of two components: (i) the heat which is released due to the direct transformation of the elastic energy into the energy of lattice vibrations during transition into a lower strain state and (ii) the heat associated with the part of the elastic energy which is first transformed into dislocation energy and then released from the system as a result of the 
reactions of the dislocations with themselves and with the film surface. The first component is not directly related to the dislocation interactions and, hence, is not involved in the patterning process. Therefore it is important to identify microscopic mechanisms capable of providing both the patterning process and the energy dissipation through the second channel. Actually, such mechanisms have been already suggested in the recent model of self-adjustment of misfit dislocations. ${ }^{9}$ This model can naturally explain the formation of the continuous slip bands by generation, glide, and annihilation of threading dislocations in the frame of a network of self-aligned multiplication sources. Note that the multiplication and annihilation processes are exactly those needed to provide the heat dissipation and, thus, the export of entropy associated with the patterning process ${ }^{3}$ through the second dissipation channel. In this case the elastic energy is first transformed into self-energy of the dislocation loops generated at every multiplication event, and further a part of this energy is transformed into heat during the growth phase of the loops due to their intersection with the surface and due to the annihilation of the threading segments moving in counter directions, as described in Ref. 9. This model is consistent with the general conclusion of Seeger and Frank ${ }^{3}$ that the mutual annihilation of dislocations plays the key role in the dislocation patterning through dissipative processes.

According to the model, the self-adjustment of misfit dislocations can happen in the network of single-precursor dislocations with the same Burgers vectors and in the more general case even due to interactions between dislocations with different Burgers vectors. The results obtained in this work show that the dislocation patterns are nucleated at the isolated cross-shaped defects composed of the orthogonal slip bands. In this situation, the precursor networks can develop around the cross-shaped defects, as a result of the dislocation branching from the primary bands in the manner found by Tuppen et al. ${ }^{12}$ for uniform $\mathrm{Si}_{1-x} \mathrm{Ge}_{x}$ films. As seen from the above discussion, the model of self-adjustment of misfit dislocations is capable of explaining in a qualitative way the experimental observations, implying among other things that the process of the strain relaxation is selforganized.

An essential element of the model is dislocation multiplication. Although the importance of this process for the strain relaxation in the thick $\mathrm{Si}_{1-x} \mathrm{Ge}_{x}$ films is widely recognized and a variety of dislocation multiplication mechanisms (spiral $^{13,22}$ and Frank-Read-type ${ }^{11,12,23-25}$ ) have been suggested in the literature, it is not yet clear ${ }^{9,26}$ which multiplication mechanism or mechanisms control the dislocation generation in $\mathrm{Si}_{1-x} \mathrm{Ge}_{x}$ films. Nevertheless, in its general context, the model does not rely on any particular multiplication source, and hence we do not exclude that a number of different multiplication mechanisms are involved in the patterning process.

The major structural features which are revealed at a large length scale and which require further elaboration are the band discontinuity and quasiperiodic character of the band distribution. The length of the bands found in the samples grown at low temperature is in the range of $\sim 0.05-0.2 \mathrm{~mm}$. A possible mechanism of the band termination is the cross slip of dislocations from an individual band into dislocation free regions or into intersecting shear bands. In the latter case the role of the cross slip in the formation of the observed dislocation structures can be twofold: First, the number of dislocations in a particular slip band can be gradually reduced by a sequence of cross-slip events. Second, the cross slip into intersecting bands allows threading dislocations to wander in the network of slip bands until they meet each other in a geometry favorable for the dislocation reactions or annihilation.

A specific feature of plastic deformation in the heteroepitaxial film systems is that, as soon as a misfit dislocation forms, it removes (or reduces) the applied stress in the adjacent region of the film. Thus the formation of the new slip bands in the graded layers takes place in the applied stress field which is well patterned by the preexisting bands and evolves during relaxation. In addition, the slip bands can interact through the long-range self-stress fields. ${ }^{1}$ These types of long-range dynamic interactions between slip bands seem to be very important for an understanding of the quasiperiodic distribution of the slip bands at the mesoscopic length scale.

\section{CONCLUSIONS}

The plastic behavior of strained, compositionally graded $\mathrm{Si}_{1-x} \mathrm{Ge}_{x}$ layers has been studied by a combination of experimental techniques sensitive to the plastic activity at different length scales. We have found that the strain relaxation process in metastable graded layers is an evolutionary propagative process which is heterogeneous from the very beginning and localized in narrow slip bands. The slip-band patterns are found to be long-range coherent and ordered at the mesoscopic length scale (on the areas at least $30 \times 30 \mu^{2}$ ). It is shown that the above results cannot be understood within the concept of "order at equilibrium." The development of the dislocation patterns is analyzed in the framework of the synergetic approach based on the Seeger-Frank treatment of dislocation ordering in solids. It is demonstrated that the strain relaxation in the thick metastable films is characterized by dissipation of large amounts of internal energy accumulated during growth and takes place far away from thermodynamic equilibrium. The results of this analysis and the observed dislocation patterns are in agreement with the qualitative model of self-adjustment of misfit dislocations, which implies self-organization of dislocation populations in graded films through the multiplication and annihilation processes.

Compared to the case of deformed metals, dislocation configurations in graded $\mathrm{Si}_{1-x} \mathrm{Ge}_{x}$ films are significantly less complex and, as was shown in this paper, can be well characterized. Thus these films represent ideal modeling systems for quantitative studies of self-organization phenomena.

\section{ACKNOWLEDGMENTS}

This work was supported by The Danish Natural Science Research Council, The Danish Technical-Science Research Council, and The Danish National Research Foundation through the Aarhus Center of Advanced Physics (ACAP), and by "Center for Nanostructures" under the Materials Development Program, MUPII. 


\section{APPENDIX: DISSIPATION COEFFICIENT FOR UNIFORM $\mathrm{Si}_{1-x} \mathrm{Ge}_{x}$ EPITAXIAL FILMS}

Let us consider a uniform $\mathrm{Si}_{1-x} \mathrm{Ge}_{x}$ film on a $\langle 001\rangle \mathrm{Si}$ substrate in which strain relief is provided by an array of orthogonal $60^{\circ}$ misfit dislocations. An explicit expression for the total energy per unit area $\left(E_{T}\right)$ for this system is given by ${ }^{17,18}$

$$
E_{T}=(2 / p) E_{d s}+E_{H},
$$

where $E_{H}$ is the energy associated with the uniform strain composed of the mismatch strain and the uniform part of the strain associated with the dislocation array, $(2 / p) E_{d s}$ is the part of the dislocation energy which is not absorbed into the relaxed mismatch strain, and $p$ is the dislocation spacing. The term $E_{H}$ is given by the equation

$$
E_{H}=2 \mu h \epsilon^{2}(1+\nu) /(1-\nu),
$$

where $\mu$ is the epilayer shear modulus, $h$ is the epilayer thickness, $\nu$ is Poisson's ratio, and $\epsilon$ is the partially relaxed strain given by

$$
\epsilon=f_{m}+b_{e} / p
$$

Here $f_{m}$ is the in-plane mismatch strain for the system without misfit dislocations, and $b_{e}$ is the component of the Bur- gers vector in the direction of the spacing $p$ and has the opposite sign of $f_{m}$. If the system relaxes from the fully strained state with a total energy $E_{T 0}$ to a relaxed state with a total energy $E_{T r}$, then the heat dissipated during the relaxation process is equal to

$$
Q=E_{T 0}-E_{T r}=E_{H 0}-E_{H r}-(2 / p) E_{d s}=\delta E-(2 / p) E_{d s},
$$

where $E_{H 0}$ and $E_{H r}$ are the energy components corresponding to the uniform strain in the unrelaxed and relaxed states, respectively, and $\delta E$ is the total amount of the mismatch energy transformed during relaxation, which is equal to

$$
\delta E=2 \mu h\left[f_{m}^{2}-\left(f_{m}+b_{e} / p\right)^{2}\right](1+\nu) /(1-\nu) .
$$

Substituting Eqs. (A4) and (A5) in the expression for dissipation coefficient $\left(K_{d e}=Q / \delta E\right)$, we obtain an analytical expression for the dissipation coefficient:

$$
K_{d e}=1-E_{d s}(1-\nu) / \mu h p(1+\nu)\left[f_{m}^{2}-\left(f m+b_{e} / p\right)^{2}\right] .
$$

We do not reproduce the expression for $E_{d s}$ due to its complex form and refer the reader to the original papers. ${ }^{17,18}$ In our calculations we were using the value of $p$ extracted from the equilibrium strain-versus-thickness curve presented in Ref. 18.
${ }^{1}$ L. P. Kubin, in Plastic Deformation and Fracture of Materials, edited by H. Mughrabi (VCH, Weinheim, 1993), pp. 137-190.

${ }^{2}$ D. Walgraef and E. C. Aifantis, Res Mech. 23, 161 (1988).

${ }^{3}$ A. Seeger and W. Frank, Solid State Phenom. 3\&4, 125 (1988).

${ }^{4}$ F. C. Frank and J. H. Van der Merwe, Proc. R. Soc. London 198, 216 (1949); 198, 2205 (1949).

${ }^{5}$ J. H. Van der Merwe, Surf. Sci. 31, 198 (1972).

${ }^{6}$ E. A. Fitzgerald, Mater. Sci. Rep. 7, 87 (1991).

${ }^{7}$ L. B. Freund, MRS Bull. 17, 52 (1992).

${ }^{8}$ R. Hull and J. C. Bean, Cr. Rev. Solid State Mater. Sci. 17, 507 (1992).

${ }^{9}$ S. Yu. Shiryaev, Philos. Mag. Lett. 68, 195 (1993).

${ }^{10}$ S. Yu. Shiryaev, F. Jensen, and J. Wulff Petersen, Appl. Phys. Lett. 64, 3305 (1994).

${ }^{11}$ F. K. LeGoues, B. S. Meyerson, J. F. Morar, and P. D. Kirchner, J. Appl. Phys. 71, 4230 (1992).

${ }^{12}$ C. G. Tuppen, C. J. Gibbings, M. Hockly, and S. G. Roberts, Appl. Phys. Lett. 56, 54 (1990).

${ }^{13}$ M. A. Capano, Phys. Rev. B 45, 11768 (1992).

${ }^{14}$ C. J. Gibbings, C. G. Tuppen, and M. Hocly, Appl. Phys. Lett. 54, 148 (1989).
${ }^{15}$ D. J. Eaglesham, E. P. Kvam, D. M. Maher, C. J. Humphreys, and J. C. Bean, Philos. Mag. A 59, 1059 (1989).

${ }^{16}$ S. R. Stiffler, C. L. Stanis, M. S. Goorsky, and K. K. Chan, J. Appl. Phys. 71, 4814 (1992).

${ }^{17}$ J, R. Willis, S. C. Jain, and R. Bullough, Philos. Mag. A 62, 115 (1990).

${ }^{18}$ T. J. Gosling, S. C. Jain, J. R. Willis, A. Atkinson, and R. Bullough, Philos. Mag. A 66, 119 (1992).

${ }^{19}$ E. A. Fitzgerald, Y.-H. Xie, D. Monroe, P. J. Silverman, J. M. Kuo, A. R. Kortan, F. A. Thiel, and B. E. Weir, J. Vac. Sci. Technol. B 10, 1807 (1992).

${ }^{20}$ J. Tersoff, Appl. Phys. Lett. 62, 693 (1993).

${ }^{21}$ P. M. Mooney, F. K. LeGoues, J. O. Chu, and S. F. Nelson, Appl. Phys. Lett. 62, 3464 (1993).

${ }^{22}$ J. Washburn and E. P. Kvam, Appl. Phys. Lett. 57, 1637 (1990).

${ }^{23}$ A. Lefebvre, C. Herberaux, C. Bouillet, and J. Di Persio, Philos. Mag. Lett. 63, 23 (1991).

${ }^{24}$ M. S. Abrahams, C. J. Buiocchi, and G. H. Olsen, J. Appl. Phys. 46, 4259 (1975).

${ }^{25}$ F. K. LeGoues, Phys. Rev. Lett. 72, 876 (1994).

${ }^{26}$ R. Beanland, J. Appl. Phys. 72, 4031 (1992). 

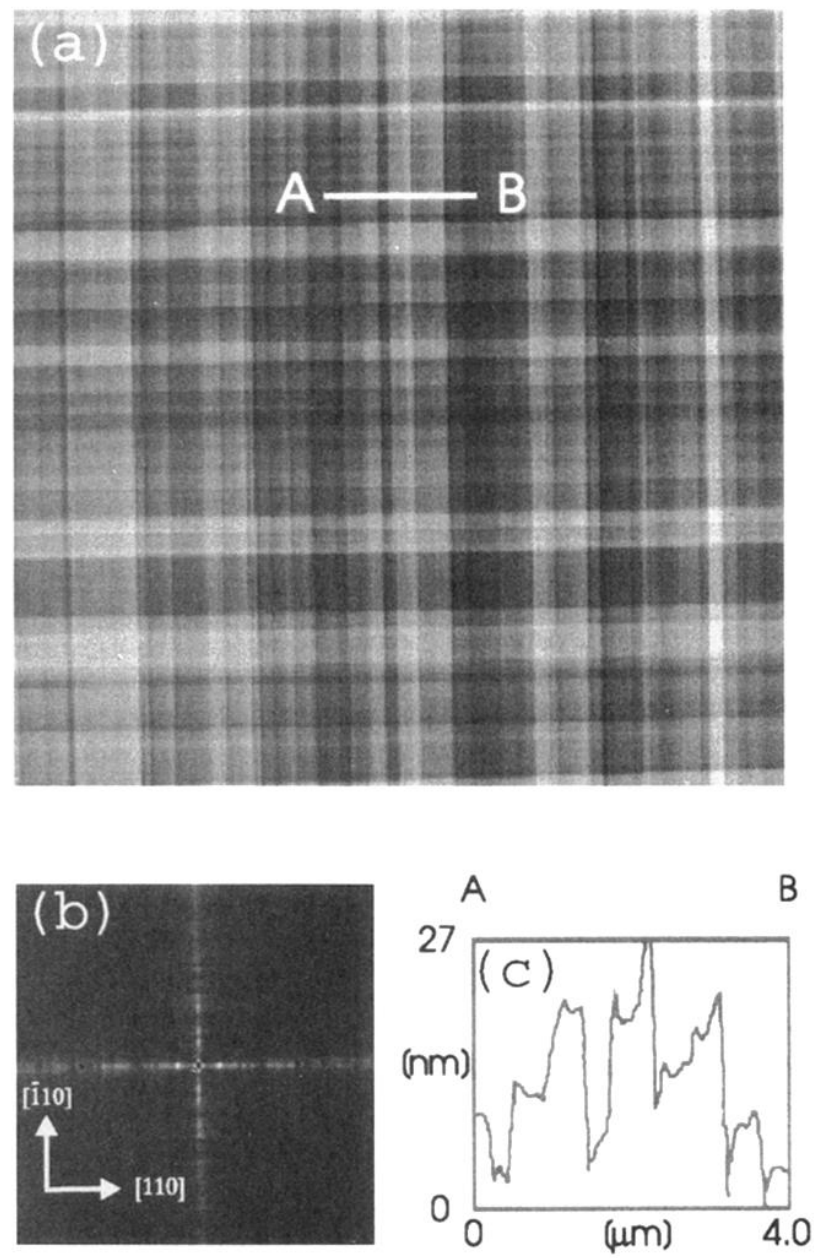

FIG. 1. AFM $\left(21 \times 21 \mu \mathrm{m}^{2}\right)$ image (a) of the slip-band pattern on the surface of a graded layer with a thickness of $1.5 \mu \mathrm{m}$ and a Ge gradient of $15 \%$ Ge per $1 \mu \mathrm{m}$, grown at $530^{\circ} \mathrm{C}$, after annealing at $620^{\circ} \mathrm{C}$ for $1 \mathrm{~h}$. The height scale (black to white) is $47 \mathrm{~nm}$. (b) and (c). Two-dimensional Fourier transform and a height profile (along the displayed line $A B$ ) obtained from (a). 


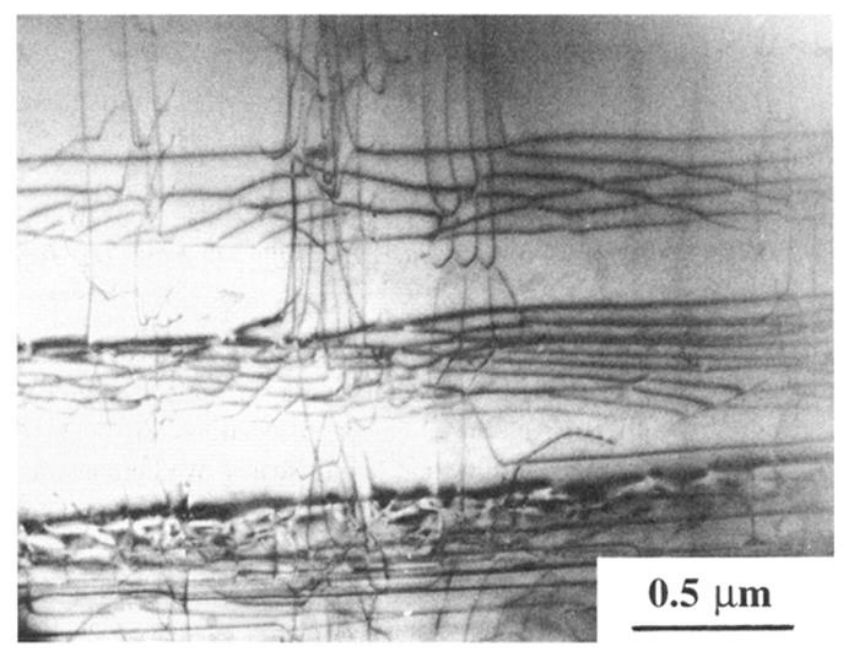

FIG. 2. Typical plan-view TEM image ( $\mathbf{g}=220$, bright field) of the slip bands observed in the sample shown in Fig. 1. 


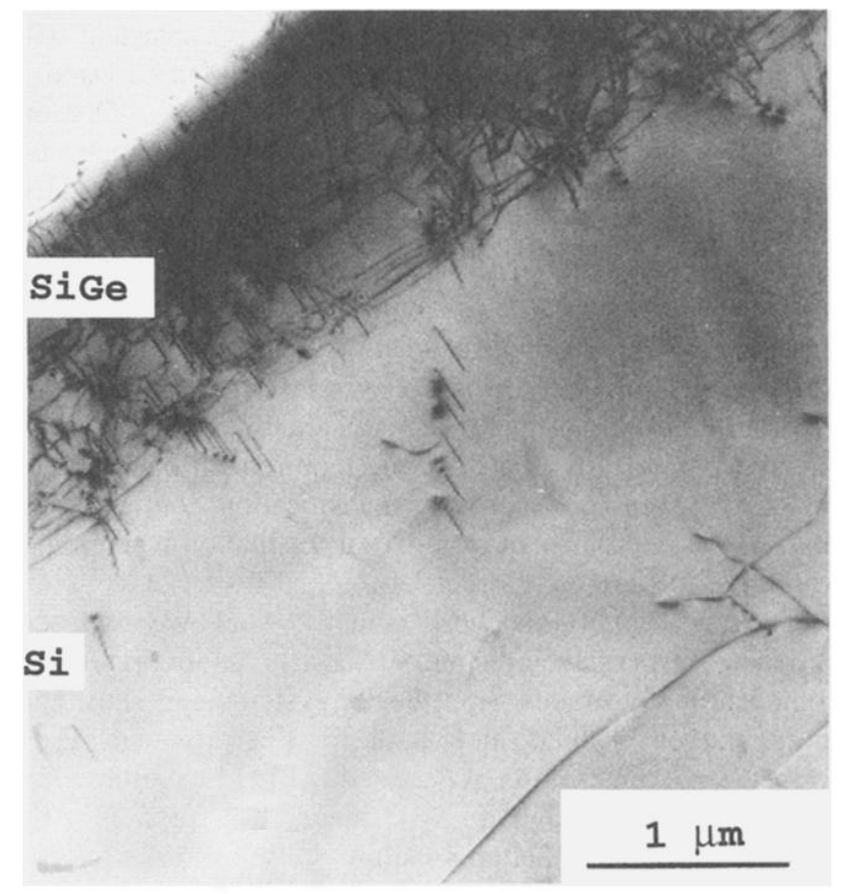

FIG. 3. Cross-sectional bright-field TEM micrograph of the sample shown in Fig. 2. The electron beam direction is about $30^{\circ}$ away from the [110] normal to the specimen plane. 

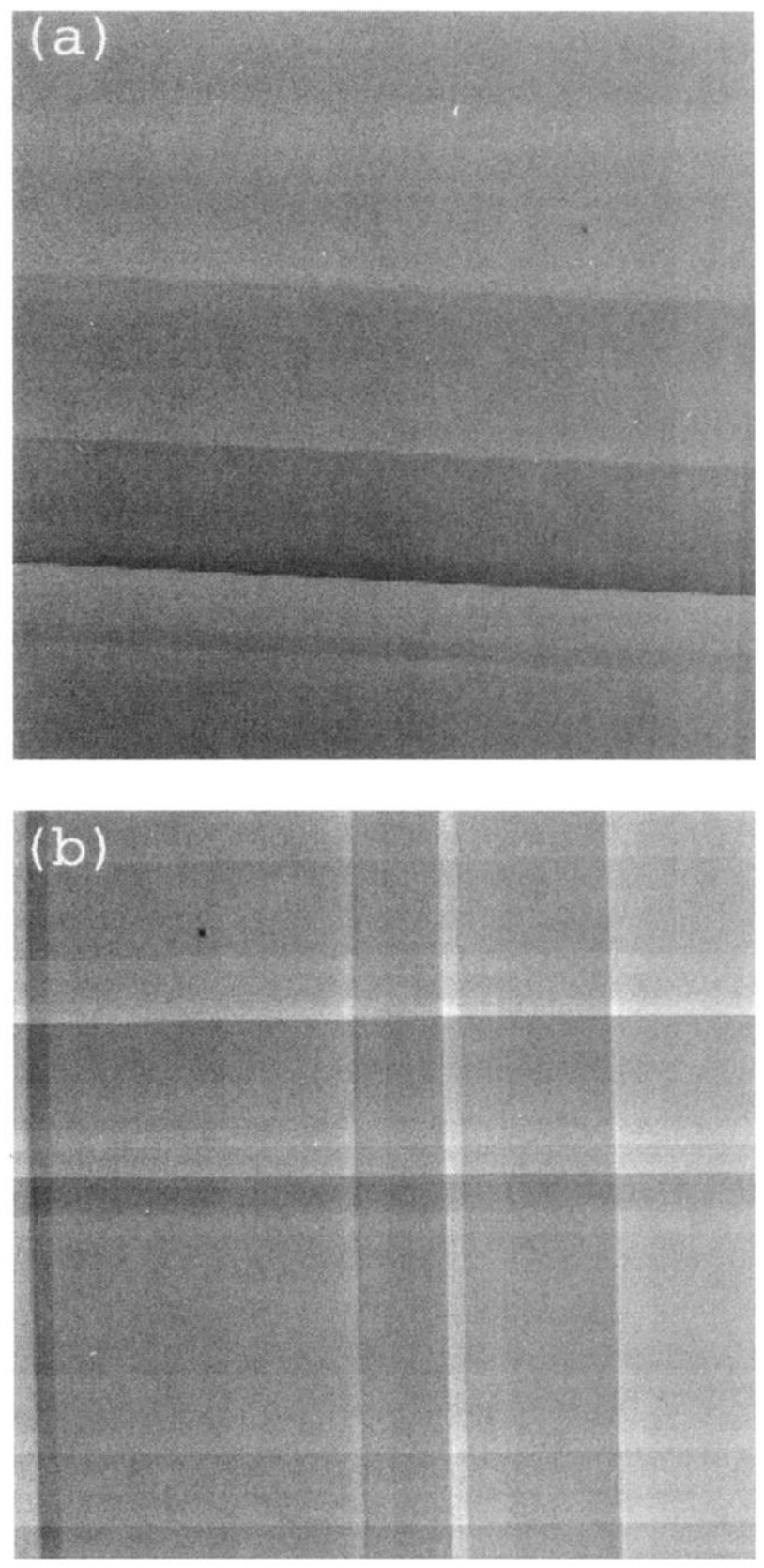

FIG. 4. AFM images characterizing the development of the slipband pattern in a $1-\mu \mathrm{m}$-thick graded layer grown at $530^{\circ} \mathrm{C}$, during the postgrowth heat treatment at $620^{\circ} \mathrm{C}$. The annealing time is 10 min (a) and $40 \mathrm{~min}$ (b), respectively. The scanned area and the height scale are $14 \times 14 \mu \mathrm{m}^{2}$ and $20 \mathrm{~nm}$, respectively, on all images. 
(a)

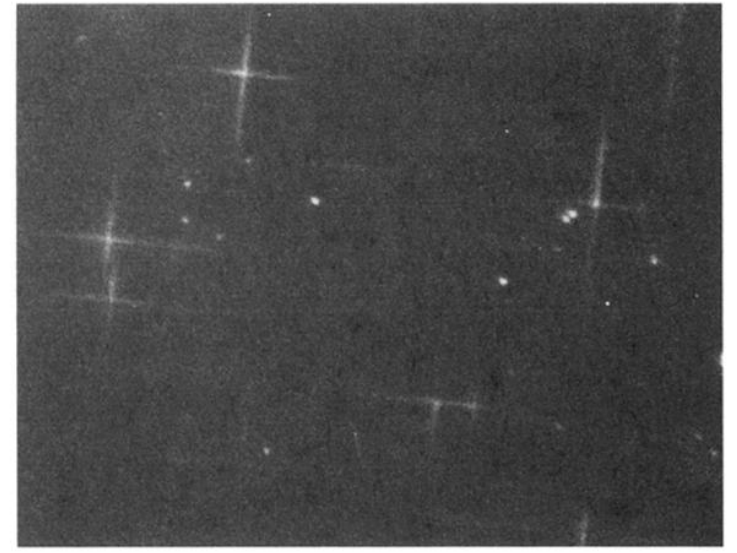

(b)

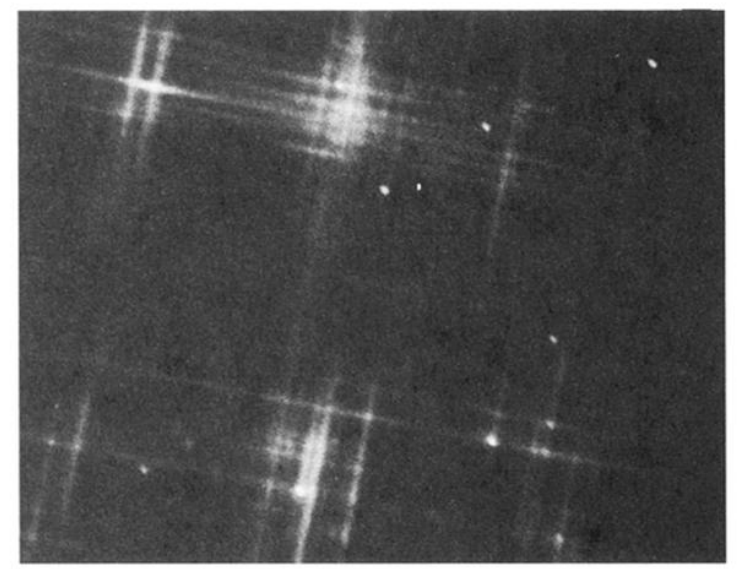

(c)

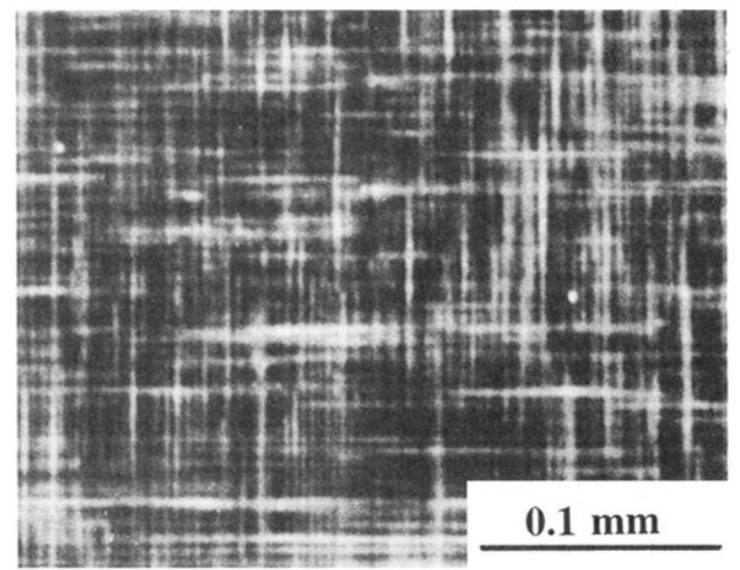

FIG. 5. Development of the slip-band pattern in graded layers during growth at $530^{\circ} \mathrm{C}$, as revealed by the optical microscopy combined with the preferential chemical etch technique. The structures are (a) 1- and (b) 1.5- $\mu \mathrm{m}$-thick graded layers, and (c) $2-\mu \mathrm{m}$ graded layer plus $2-\mu \mathrm{m}$ uniform cap. 


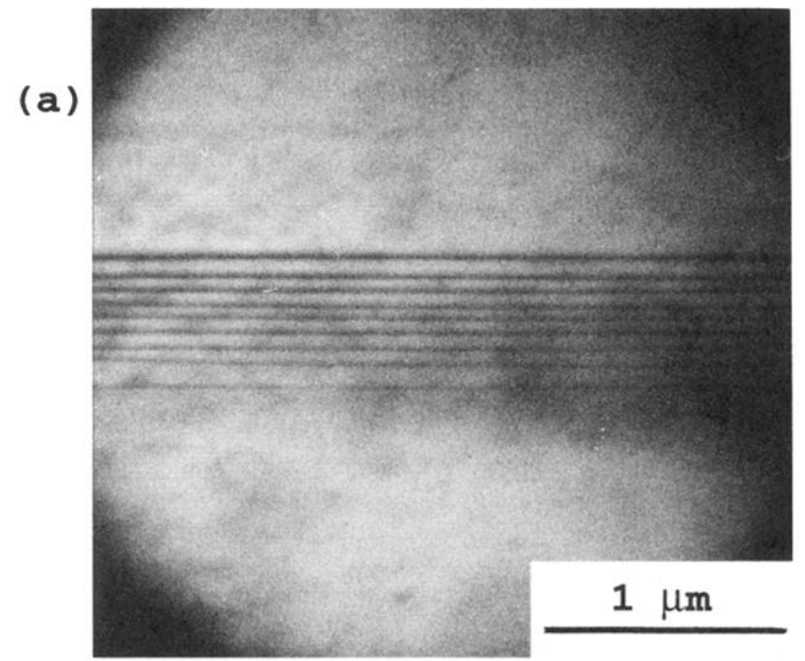

(b)

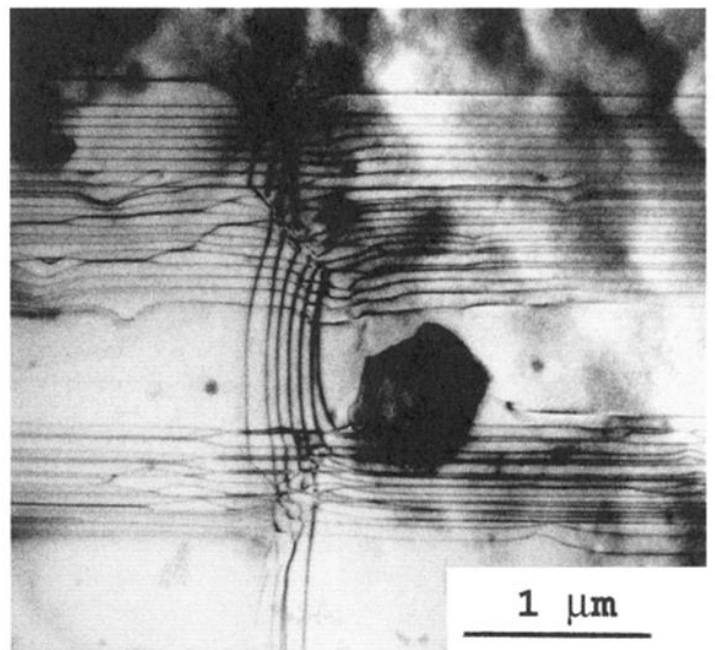

FIG. 6. Plan-view bright-field TEM images of the 1- $\mu$ m-thick graded layer grown at $530^{\circ} \mathrm{C}$ : (a) the separated slip band and (b) the more complicated structure composed of the central defect and the orthogonal intersecting slip bands. 

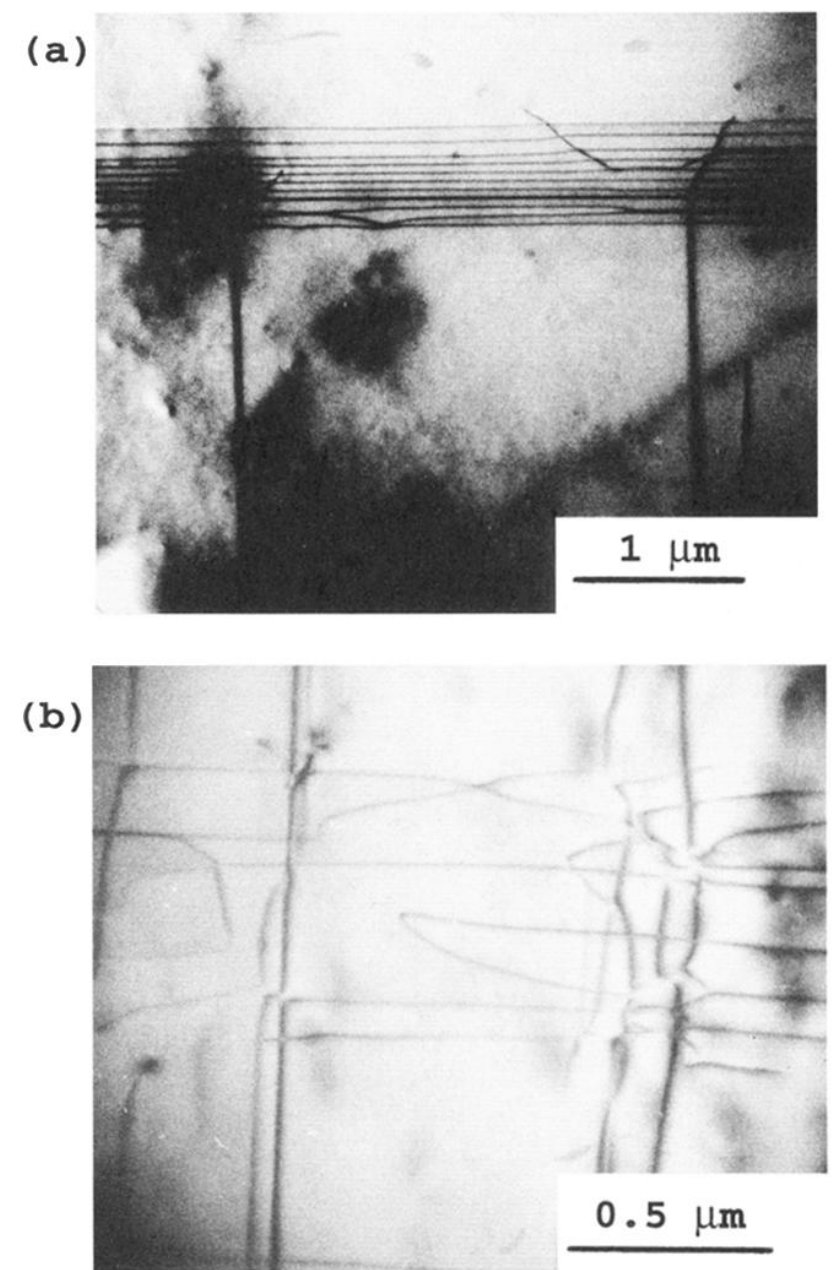

FIG. 7. Plan-view bright-field TEM images of the dislocation structures observed in the $1.5-\mu \mathrm{m}$-thick graded layers grown at $530{ }^{\circ} \mathrm{C}$ : (a) the structure composed of the slip bands and individual dislocations and (b) the intersections of misfit dislocations involving well-defined bowing loops. 


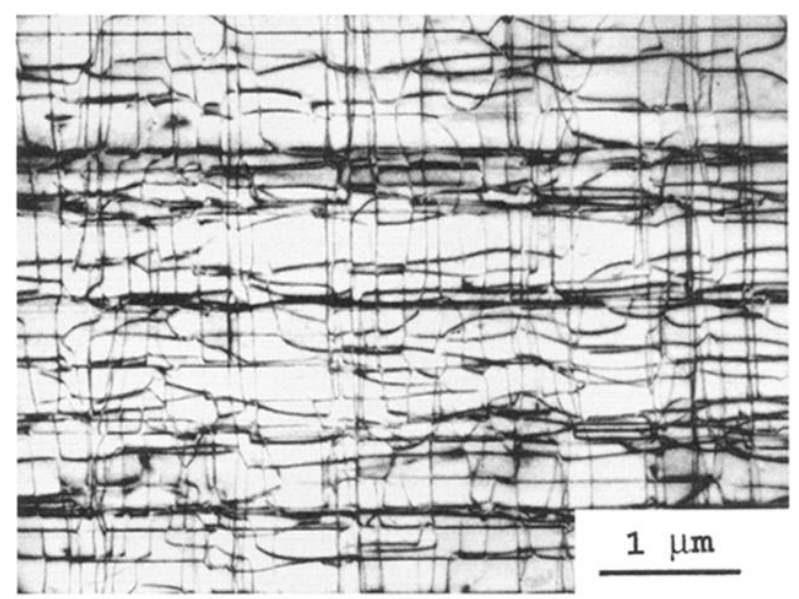

FIG. 8. Typical TEM image of the dislocation pattern found in a 1 - $\mu \mathrm{m}$-thick graded layer with a Ge gradient of $15 \%$ Ge per $1 \mu \mathrm{m}$, grown at high $\left(850^{\circ} \mathrm{C}\right)$ temperature. 